\title{
Vocabulary Learning Strategies Preference Used By The Seventh Grade Students of SMP Negeri 1 Mlati
}

\author{
Bernadeta Ajeng Setia Pratami ${ }^{1}$, Margana ${ }^{2}$ \\ \{ajengsetyanto@gmail.com,margana@uny.ac.id ${ }^{2}$ \} \\ ${ }^{1,2}$ Yogyakarta State University, Indonesia
}

\begin{abstract}
This research investigated English vocabulary learning strategies employed by the seventh-grade students of SMP Negeri 1 Mlati. This research aimed to find the most and least frequently vocabulary learning strategies (VLS) employed by the seventh-grade students of SMP Negeri 1 Mlati. The participants of this research were one hundred and twenty-eight students in SMP Negeri 1 Mlati. A 20-item questionnaire was adapted from Schmitt's Vocabulary Learning Strategies Taxonomy. The research data were analyzed utilizing descriptive and inferential statistics through SPSS program version 23. The result of this survey revealed that the students belonged to low users of VLS. Social strategies were the most frequently used strategies. Memory strategies were the least frequently utilized strategies. The finding also revealed that there was no significant difference in the use of VLS among male and female students.
\end{abstract}

Keywords: vocabulary learning strategies, social strategies, memory strategies.

\section{INTRODUCTION}

Vocabulary is defined as the words utilized to communicate effectively in speaking and listening [1]. Vocabulary is fundamental to establish language and plays a vital role in communication [2]. Vocabulary is a primary component of language proficiency and provides a basis for speaking, listening, reading, and writing [3]. By having a vocabulary, people can express their ideas and understand other's well. Without adequate vocabulary acquisition, learners will achieve less than what they get, and they might be discouraged to involve in speaking, listening, reading, and writing.

Reading is one skill in English language skills. Reading refers to the thinking process, which organizes two persons doing together between an author and a reader [4]. Reading means developing relationships among ideas. When you are reading, automatically, you bring your vocabulary understanding, your ability to find its meaning, and your attitude too. Rama et.all [5] revealed that the students are exposed to meet new vocabulary, syntax, and cultures in reading learning. Vocabulary is a part of reading. Thus, vocabulary needs to be learned and mastered by the students since it is essential in reading. If the students know the words, they will be able to create an understanding of a particular text better. 
Moreover, building vocabulary is essential for English foreign language learners. Zhihong [6] also stated that having a limited vocabulary is an obstacle for the students in learning a foreign language. It is one problem that the students faced in vocabulary learning. For that reason, Zhang [7] revealed that VLS is an essential factor for foreign vocabulary acquisition. It is a fact that the use of VLS influences the success of foreign vocabulary acquisition. Ghazal [8] pointed out that teaching vocabulary includes both teaching specific words and teaching the students with proper learning strategies to build their vocabulary knowledge. To overcome the problem that appeared related to vocabulary learning, the teachers help the students with learning strategies. Thornbury [9] revealed that the students who are able to expand their on VLS are good learners. Thus, students require recognizing different kinds of strategies for learning vocabulary, which is appropriate for them in order to improve their vocabulary acquisition.

Intaraprasert [10] defined that VLS are several techniques employed to find out the meaning of new words and enrich the knowledge of words in learning the language. However, there are other clarifications of learning strategies proposed by Oxford [11]. According to Oxford, learning strategies are particular actions, behaviors, steps, or techniques used by learners to use in order to improve their use of the second language. Oxford's taxonomy on learning strategies covers direct and indirect strategies. Learning strategies can be defined as any set of operations, steps, plans, and routines that are used by second language learners to obtain store, retrieve, and use the information they acquire [12]. Gu [13] defined learning strategies as the selection of any actions that learners used in order to achieve a particular goal or task. The learning strategies are used in the problem-solving environment classroom as an effort to discover the most effective way to do what is required. Hence, the language learning strategies help learners in selecting the appropriate ways to improve their proficiency and achievement of the target language [12]. O'Malley et.all [14] proposed three types of strategies, namely metacognitive, cognitive, and social or effective strategies in learning strategies. Schmitt [15] stated that memorizing, repeating, and note-taking on words are the most commonly used strategies for second language learners to improve their vocabulary acquisition. Hence, Schmitt develops a taxonomy of VLS, which is divided into five main strategies. Those five main strategies are determination strategies, social strategies, memory strategies, cognitive strategies, and metacognitive strategies.

Bridging the fact above, it is necessary to instill VLS for Junior High School students since the students study English as the compulsory subject in the school. This research is aimed to investigate the use of VLS employed by the seventh-grade students of SMP Negeri 1 Mlati. It examines the level of VLS, the most and least frequently VLS used by the students. In addition, it also examines whether there is a significant difference in the use of VLS by male and female students. This research might be useful for English teachers to know the strategies which might be employed by students to maximize their vocabulary learning in reading class. Then, it can also be employed as a preliminary study to conduct further study on the same field. The researcher utilizes VLS proposed by Schmitt.

Schmitt [15] stated that VLSs are commonly used by language learners are memorizing, repeating, and taking notes on the lexical words. He pointed out that beginner learner usually uses strategies such as memorization and repetition, whereas advanced learners use strategies such as consolidation and determination strategies.

Moreover, Schmitt proposed a list of VLSs that are categorized based on the purposes; strategies to discover words' meaning and strategies to consolidate a word that has been encountered. Those two categories are composed of a taxonomy proposed that includes a variety of different strategies. Schmitt [15] divided the taxonomy into five main strategies, 
namely determination strategies, social strategies, memory strategies, cognitive strategies, and metacognitive strategies.

Determination strategies are strategies that are useful for students to discover the meaning of the unknown words by themselves. The strategies are individual learning strategies that enable students to encounter the words' meaning without having peer assistance. The examples of determination strategies are guessing words from context and using a bilingual dictionary.

Social strategies enable students to interact with their friends or teachers in order to encounter the meaning of unknown words. Students can employ this kind of strategies by asking their classmates or teachers about synonym, paraphrase, or L1 translation of the unknown words. Moreover, social strategies can be used to find the meaning of unknown words by studying or practicing the meaning in a group.

Memory strategies employ mental processing to learn the new word by connecting new words with some existing or background knowledge. A new word can be connected to students' existing knowledge by using some imagery or grouping. Schmitt [15] revealed that learning new words can be done by employing pictures. Similarly, relating new words with their synonym and antonym as well as reciting rhymes may be useful to help students memorize new words. Moreover, memorization can be carried out by focusing on the spelling or pronunciation of the words. By connecting L1 words that sound like the target L2 words can help students memorize the words. In addition, the use of physical activity also facilitates students' word recollection.

Cognitive strategies focus more on mechanical processing. Students can always repeat the pronunciation of new words, writing new words, taking notes, and keeping a vocabulary notebook in order to help them learn new words. Metacognitive strategies cover monitoring, decision-making, and evaluation processes. Metacognitive strategies allow students to select appropriate learning strategies in order to control their learning process. Strategies such as using English movie, songs and news and taking exercises are examples of metacognitive strategies which can be used by students. Table 1 and Table 2 below presents the taxonomy of VLS by Schmitt [15].

Table 1. A Simple Taxonomy of Vocabulary Learning Strategies

\begin{tabular}{ll}
\hline \multicolumn{2}{c}{ Vocabulary Learning Strategy (VLS) } \\
\hline 1.Strategies to discover a new word & 2. Strategies to consolidate a word it \\
meaning & has been encountered \\
Determination strategies (DET) & Social strategies (SOC) \\
Social strategies (SOC) & Memory strategies (MEM) \\
& Cognitive strategies (COG) \\
& Metacognitive strategies (MET) \\
\hline
\end{tabular}

Table 2. A Taxonomy of Vocabulary Learning Strategies [12]

\begin{tabular}{l}
\hline Strategy Group \\
\hline Strategies to consolidate a word when it has been encountered \\
\hline DET Analyze part of speech \\
DET Analyze affixes and roots \\
DET Check for L1 cognate \\
DET Analyze any available pictures or gestures
\end{tabular}


DET Guess from textual context

DET Bilingual dictionary

DET Monolingual dictionaries

DET Word lists

DET Flashcards

SOC Ask the teacher for L1 translation

SOC Ask the teacher to paraphrase or find a synonym of new words

SOC Ask the teacher for a sentence including the new word

SOC Ask classmates for meaning

SOC Discover new meaning in group work activity

Strategies to consolidate a word when it has been encountered

SOC Study and have the exercise meaning in a group

SOC Teacher checks students' flashcards word lists for accuracy

SOC Interact with native-speakers

MEM Study word with a pictorial representation of its meaning

MEM Image word's meaning

MEM Connect word to a personal experience

MEM Associate the word with its coordinates

MEM Connect the word to synonyms and antonyms

MEM Use semantic maps

MEM Use 'scales' for gradable adjectives

MEM Peg Method

MEM Loci Method

MEM Group words together to study them

MEM Group words together spatially on a page

MEM Utilize new word in sentences

MEM Group words together within a storyline

MEM Study the spelling of a word

MEM Study the sound of a word

MEM Say the new word aloud when studying

MEM Image word form

MEM Underline initial letter of the word

MEM Configuration

MEM Use Keyword Method

MEM Affixes and roots

MEM Part of speech

MEM Paraphrase the word's meaning

MEM Use cognates in study

MEM Learn the words of idiom together

MEM Use physical action when learning a word

MEM Use semantic feature grids

COG Verbal repetition

COG Written repetition

COG Word lists

COG Flashcards

COG Take notes in class

COG Use the vocabulary section in your textbook 
COG Listen to the tape of word lists

COG Put English labels on physical objects

COG Keep a vocabulary notebook

MET Use English-language media (songs, movies, newscast, etc.)

MET Testing oneself with word tests

MET Use spaced word practice

MET Skip or pass the new word

MET Continue to study over time

\section{METHOD}

This research was based on the principle that the students employed different VLS in acquiring vocabulary. The theoretical support came from Schmitt's [15] taxonomy of VLS, which were categorized into four main strategies, namely Social (SOC), Memory (MEM), Cognitive (COG), and Metacognitive (MET). This research employed the descriptive survey method to determine the VLS used by the students as well as the most frequently used strategies.

This research was conducted in SMPN 1 Mlati, which is located at Sanggrahan, Tirtoadi, Mlati, Kabupaten Sleman, Yogyakarta city. It was on the twenty of June 2019. The participants were the seventh-grade student of SMP Negeri 1 Mlati in the year 2018/2019 with a total of 128 students from class VII A, B, C, and D. They were studying in the seventh grade, so that they have been studying English for about two until seventh years. There were 53 female respondents and 75 male respondents.

This research applied two kinds of research instruments, namely, questionnaire and interview guideline. The VLS questionnaire was employed as the primary instrument to find the preference of the students' VLS. It was adapted based on Schmitt's taxonomy. There were two parts of the questionnaire. The first part contained the respondents' gender and grade level. The second part contained 20 questions. However, there were only four categories out of five, which were adapted for the questionnaire. The VLS questionnaire only focused on the strategies which were used to consolidate the words which have been encountered. The strategies were Social strategies (SOC), Memory Strategies (MEM), Cognitive Strategies (COG), and Metacognitive strategies (MET). A 20 question covered four strategies: items 1-7 belonged to memory strategies (MEM), items 8-10 belonged to social strategies (SOC), items 11-16 belonged to cognitive strategies (COG), and items 16-20 belonged to metacognitive strategies.

The questionnaire required the students to indicate how often they utilized the strategies. The level of VLS use was determined using indicators expressed on the four-point scale: 4always, 3-often, 2-sometimes, and 0-never. The respondents were instructed to fill the questionnaire by checking the brackets that correspond to their answers. The second instrument employed was an interview guideline. The interview was conducted after the result of the questionnaire was analyzed. It was a structured interview. The aim was to confirm the result of data analysis.

In this section, the researcher employed the SPSS program version 23 in presenting the data. The researcher analyzed the students' questionnaires in order to answer the three 
research questions. Descriptive statistics were utilized to discover the frequencies, percentages, means, and standard deviations of all strategies used. Furthermore, the Independent Sample T-test was employed to find out whether there was a significant difference between the students' gender and the use of vocabulary learning strategies (VLS).

\section{RESULT}

\section{The Overall Vocabulary Strategy Use and its Level}

The result showed that in four categories of VLS which were used to consolidate the words which have been encountered, the students belonged to low users of VLS. The results revealed that the students' mean score was 2.45 . Hence, it belonged to low users of VLS. As stated by Oxford [11] about the system of scoring, the mean score 1.00-2.49 belongs to low strategy use, mean score 2.50-3.49 belongs to medium strategy use, and mean score 3.50-5.00 belongs to high strategy use. The students most frequently used Social strategy. It reached the highest mean score of 2.61. On the other hand, memory strategy was the least used strategy with the lowest mean score of 2.41. Cognitive strategy and metacognitive strategy had the same mean scores 2.43. The result was shown in Table 3 below.

Table 3. The Use of the Four Categories of VLS utilized by the Students

\begin{tabular}{ccccc}
\hline Strategy Category & Mean & Std. Deviation (SD) & Rank & $\begin{array}{c}\text { Strategy } \\
\text { Use }\end{array}$ \\
\hline Social (SOC) & 2.61 &, 47091 & 1 & Medium \\
Cognitive (COG) & 2.43 &, 52132 & 2 & Low \\
Metacognitive (MET) & 2.43 &, 49720 & 2 & Low \\
Memory (MEM) & 2.41 &, 43406 & 3 & Low \\
Overall Strategies & 2.45 &, 35989 & Low \\
\hline
\end{tabular}

\section{The Frequency of Usage of VLS for each Category}

The result of each strategy was presented in table 4, table 5, table 6, and table 7 below.

Table 4. Descriptive Statistics of Strategy Use in Individual Item of Social (SOC)

\begin{tabular}{lccc}
\hline \multicolumn{1}{c}{ Item and Strategy } & Mean & SD & Rank \\
\hline $\begin{array}{l}\text { 9. I ask classmates for meaning when I } \\
\text { forget the meaning of a word. }\end{array}$ & 2.75 & .664 & 1 \\
$\begin{array}{l}\text { 10. I study vocabulary with classmates in } \\
\text { groups. }\end{array}$ & 2.65 & .727 & 2 \\
$\begin{array}{l}\text { 8. I ask my teacher for the new word's } \\
\text { synonyms and antonyms. }\end{array}$ & 2.46 & .762 & 3 \\
\hline
\end{tabular}

Social strategies in vocabulary learning were employed for consolidating the meaning of the unknown words by interacting with friends or teachers. From the table above, the most frequently the social strategy used by the respondents was item 9, "I ask classmates for meaning when I forget the meaning of a word" (mean= 2.75). On the other hand, the strategy which the respondents used least frequently was item 8; "I ask my teacher for the new word's synonym and antonym" ( mean $=2.46)$. 
Table 5. Descriptive Statistics of Strategy Use in Individual Item of Cognitive (COG)

\begin{tabular}{lccc}
\hline \multicolumn{1}{c}{ Item and Strategy } & Mean & SD & Rank \\
\hline $\begin{array}{l}\text { 13. I write, underlined, and colors the } \\
\text { words that I just met. }\end{array}$ & 2.74 & .806 & 1 \\
11. I repeatedly say the words in my mind. & 2.70 & .757 & 2 \\
12. I make my own vocabulary with its & 2.63 & .841 & 3 \\
meanings in my note. & & & \\
14. I repeatedly write the words. & 2.24 & .673 & 4 \\
15. I use a flashcard. & 1.84 & .637 & 5 \\
\hline
\end{tabular}

Table 5 above showed that the cognitive strategy that the students employed most frequently was item 13, "I write, underlined, and colors the words that I just met" (mean $=2.74$ ). However, item 15, "I use a flashcard" was the least frequently used with mean $=1.84$.

Table 6. Descriptive Statistics of Strategy Use in Individual Item of Metacognitive (MET)

\begin{tabular}{llll}
\hline \multicolumn{1}{c}{ Item and Strategy } & Mean & SD & Rank \\
\hline $\begin{array}{l}\text { 19. I listen to English songs. } \\
\text { 20. I use exercises to test my vocabulary }\end{array}$ & 2.79 & .939 & .65 \\
knowledge. & & .769 & 2 \\
$\begin{array}{l}\text { 16. I watch an English movie with } \\
\quad \text { English subtitles. }\end{array}$ & 2.48 & .878 & 3 \\
$\begin{array}{l}\text { 18. I pay more attention to the English } \\
\quad \text { words that I have just met. }\end{array}$ & 2.38 & .676 & 4 \\
$\begin{array}{l}\text { 17. I skip the difficult words I find when } \\
\text { reading. }\end{array}$ & 1.86 & .707 & 5 \\
\hline
\end{tabular}

Based on the result of table 6 above, the most frequently employed of the metacognitive strategy was item 19, "I listen to English songs" (mean =2.79). Meanwhile, item 20; "I skip the difficult words I find when reading," was the least-used strategy for vocabulary learning $($ mean $=1.86)$.

Table 7. Descriptive Statistics of Strategy Use in Individual Item of Memory (MEM)

\begin{tabular}{lccc}
\hline \multicolumn{1}{c}{ Item and Strategy } & Mean & SD & Rank \\
\hline $\begin{array}{l}\text { 2. I remember the new vocabulary by imagining } \\
\text { or describing the word in my mind. }\end{array}$ & 2.80 & .699 & 1 \\
$\begin{array}{l}\text { 7. I study the spelling of a word. } \\
\text { 4. I use the new words into sentences so I can }\end{array}$ & 2.62 & .824 & 2 \\
remember. & & .684 & 3 \\
$\begin{array}{l}\text { 6. I link the new word to another English word } \\
\text { with a similar sound. }\end{array}$ & 2.39 & .734 & 4 \\
$\begin{array}{l}\text { 3. I speak out-loud when I find it first. } \\
\text { 1. I make pictures based on the words found to }\end{array}$ & 2.34 & .818 & 5 \\
make it easier to remember the word. & & .711 & 6 \\
5. I use physical actions when learning words. & 2.13 & & \\
\end{tabular}

According to Memory strategies, the results showed that the students most frequently used was strategy item 2 "I remember the new vocabulary by imagining or describing the word in 
my mind" (mean $=2.80)$. Meanwhile, the least used strategy was item 5 "I use physical actions when learning words." (mean $=2.13)$.

\section{The Five Most and Least Used Item of VLS Strategies Used by the Students}

Table 8. The Five Most Used Strategies by the Students

\begin{tabular}{|c|c|c|c|c|}
\hline Item and Strategy & VLS Category & Mean & SD & Rank \\
\hline $\begin{array}{l}\text { 1. I remember the new vocabulary by } \\
\text { imagining or describing the word in my } \\
\text { mind. }\end{array}$ & MEM & 2.80 & .699 & 1 \\
\hline 19. I listen to English songs. & MET & 2.79 & .939 & 2 \\
\hline $\begin{array}{l}\text { 9. I ask classmates for meaning when I forget } \\
\text { the meaning of a word. }\end{array}$ & SOC & 2.75 & .664 & 3 \\
\hline $\begin{array}{l}\text { 13. I write, underline and color the words that } \\
\text { I just met. }\end{array}$ & COG & 2.74 & .806 & 4 \\
\hline 11. I repeatedly say the words in my mind. & $\mathrm{COG}$ & 2.70 & .757 & 5 \\
\hline
\end{tabular}

Regarding the most frequently used VLS by the students of this research, it pointed out that one strategy was in the memory category (item 2), one strategy was in metacognitive category (item 19), one strategy was in the social category (item 9), and two strategies were in the cognitive category (item 13 and 11). Strategy item 2," I remember the new vocabulary by imagining or describing the word in my mind," was employed with the highest mean score of 2.80. Other most frequently employed strategies were item 19 "I listen to English songs" $($ mean $=2.79)$, strategy item 9 "I ask classmates for meaning when I forget the meaning of a word" (mean= 2.75), strategy item 13 "I write, underline and color the words that I just met" $($ mean $=2.74)$, strategy item 11 " I repeatedly say the words in my mind" (mean=2.70).

Table 9. The Five Least Used Strategies by the Students

\begin{tabular}{|c|c|c|c|c|}
\hline Item and Strategy & VLS Category & Mean & SD & Rank \\
\hline 15. I use a flashcard. & $\mathrm{COG}$ & 1.84 & .637 & 1 \\
\hline $\begin{array}{l}\text { 17. I skip the difficult words I find when } \\
\text { reading. }\end{array}$ & MET & 1.86 & .707 & 2 \\
\hline 5. I use physical actions when learning words. & MEM & 2.13 & .774 & 3 \\
\hline $\begin{array}{l}\text { 1. I make pictures based on the words found } \\
\text { to make it easier to remember the word. }\end{array}$ & MEM & 2.17 & .711 & 4 \\
\hline 14. I repeatedly write the words. & $\mathrm{COG}$ & 2.24 & .673 & 5 \\
\hline
\end{tabular}

As the table 9 showed that the least frequently used strategy among 128 VLS by the students of this study were two strategies from cognitive categories (item 15 and 14), one strategy from metacognitive category (item 17), and two strategies from memory category (item 5 and 1). Strategy item 15 "I use a flashcard" was employed the lowest mean score of 1.84, continued by strategy item 17 "I skip the difficult words I find when reading" (mean= 1.86), strategy item 5 "I use physical actions when learning words" (mean=2.13), strategy 1 "I make pictures based on the words found to make it easier to remember the word" (mean= $2.17)$, strategy 14 "I repeatedly write the words" (mean= 2.24). 


\section{Significant Differences of VLS Use Based on Gender}

Table 10. Independent Sample t-test on the Use of Four Categories of VLS by Gender

\begin{tabular}{|c|c|c|c|c|c|c|c|c|c|}
\hline \multirow[t]{2}{*}{ VLS Category } & \multicolumn{3}{|c|}{ Male Students } & \multicolumn{3}{|c|}{ Female Students } & \multirow[b]{2}{*}{$\mathrm{t}$} & \multirow[b]{2}{*}{$\mathrm{df}$} & \multirow[b]{2}{*}{$\begin{array}{l}\text { Sig. (2- } \\
\text { tailed) }\end{array}$} \\
\hline & $\mathrm{N}$ & Mean & $\mathrm{SD}$ & $\mathrm{N}$ & Mean & $\mathrm{SD}$ & & & \\
\hline Social (SOC) & 53 & 2.58 & .4942 & 75 & 2.65 & .4549 &,- 831 & 126 & .408 \\
\hline $\begin{array}{l}\text { Cognitive } \\
(\mathrm{COG})\end{array}$ & 53 & 2.33 & .5885 & 75 & 2.50 & .4584 & -1.897 & 126 & .060 \\
\hline $\begin{array}{l}\text { Metacognitive } \\
\text { (MET) }\end{array}$ & 53 & 2.48 & .5646 & 75 & 2.40 & .4448 & .845 & 126 & .400 \\
\hline $\begin{array}{l}\text { Memory } \\
\text { (MEM) }\end{array}$ & 53 & 2.39 & .4433 & 75 & 2.43 & .4295 & .542 & 126 & .589 \\
\hline
\end{tabular}

From the table above, the result of Independent Sample t-test indicated that $\mathrm{p}$ values for all four categories of VLS were bigger than significance .05 ( $\mathrm{p}$-value > .05): social strategies with $\mathrm{p}=.408$, cognitive strategies with $\mathrm{p}=.060$, metacognitive strategies with $\mathrm{p}=.400$ and memory strategies with $\mathrm{p}=.589$. It means that there was no significant difference in social, cognitive, metacognitive, and memory VLS between male and female students. Nevertheless, the results of Independent Sample t-test individual items for four VLS showed a significant difference in the mean scores in table 11 .

Table 11. Significant Difference of Individual Items Used by Gender

\begin{tabular}{llllllll}
\hline Item and Strategy & Gender & $\mathrm{N}$ & Mean & $\mathrm{SD}$ & $\mathrm{t}$ & $\mathrm{df}$ & $\begin{array}{l}\text { Sig. } \\
\text { tailed) }\end{array}$ \\
\hline $\begin{array}{l}\text { 8. I ask my teacher for the } \\
\text { new word's synonyms }\end{array}$ & Male & 53 & 2.26 & .711 & -2.506 & 126 & .013 \\
and antonyms (SOC). & & & & & & & \\
$\begin{array}{l}\text { 10. I study vocabulary } \\
\text { with classmates in groups }\end{array}$ & Male & 53 & 2.85 & .818 & 2.687 & 126 & .008 \\
$\begin{array}{l}\text { (SOC). } \\
\text { 12. I make my own }\end{array}$ & Male & 53 & 2.51 & .623 & & & \\
vocabulary with its & Female & 75 & 2.42 & .887 & -2.514 & 126 & .013 \\
meanings in my note & & & & .776 & & & \\
(COG). & & & & & & & \\
13. I write, underline, and & Male & 53 & 2.47 & .868 & -3.315 & 126 & .001 \\
color the words that I just & Female & 75 & 2.93 & .704 & & & \\
met (COG). & & & & & & & \\
17. I skip the difficult & Male & 53 & 2.02 & .820 & 2.177 & 126 & .031 \\
words I find when reading & Female & 75 & 1.75 & .595 & & & \\
(MET). & & & & & & & \\
\hline
\end{tabular}

Based on the table above, it indicated that male students received higher significant scores with p-value below .05 ( $\mathrm{p}<.05)$ compared to female students in two strategies, namely strategy item 10 (SOC) "I study vocabulary with classmates in groups" with $\mathrm{t}(126)=2.687$, $\mathrm{p}=.008$, and strategy item 17 (MET) "I skip the difficult words I find when reading" with $\mathrm{t}(126)=2.177, \mathrm{p}=.031$. Female students received higher significant scores with $\mathrm{p}$-value below .05 $(\mathrm{p}<.05)$ compared to male students in three strategies, strategy item 8 (SOC) "I ask my teacher for the new word's synonyms and antonyms" with $\mathrm{t}(126)=-2.506, \mathrm{p}=.013$, 
strategy item 12 (COG) "I make my vocabulary with its meanings in my note with $\mathrm{t}(126)=$ $2.514, \mathrm{p}=.013$ and strategy item 13 (COG) "I write, underline and color the words that I just met" with $\mathrm{t}(126)=-3.315, \mathrm{p}=.001$.

\section{Discussion}

The result of this research revealed that the seventh-grade students of SMP Negeri 1 Mlati were low users of VLS. The finding showed that the students were medium strategy users for social strategies and low strategy users of cognitive, metacognitive, and memory strategies. The result also revealed that most students employed social strategies to deal with the new words they encountered during the process of English learning in the class. From table 4, the social strategies provided aids for students in their learning process. The most frequently used strategy was by asking classmates for meaning when they forget the meaning of the word.

Vygotsky [16] stated that the social environment could affect the process of students' learning by having interaction among peers and teachers. The students felt enjoy and active in learning; they actively communicated with their friends. The students could have a discussion with their friends in learning vocabulary.

The interview result also supported this result. One of the interviewees agreed that by asking classmates for meaning when they forget the meaning of a word made the process of remembering words became easier.

"I frequently ask my classmates. When I do not know the meaning, I feel that my friends can explain clearly the meaning of the unknown words. It is helpful for me since I become to remember the unknown words better."

Moreover, most students learned vocabulary with classmates in groups (see Table 4). From the result, the students tended to do group working in learning vocabulary rather than did it individually. Then, the teacher could make group discussions in developing learning, which optimized the learners' learning. In social strategies, the students enabled them to interact with their peers or teachers to deal with unknown words and studying the meaning in a group. Cooperative learning could be a strategy in learning vocabulary. Cooperative learning made students work together in pairs and groups. The students shared the information they possessed in groups [17]. They worked as a team. Therefore, they must work together to achieve goals successfully. According to Slavin [18], cooperative learning was one of the teaching methods where the students perform in a group to assist one another learning academic contest. In this paper, cooperative learning was a learning way in which the students do not learn by themselves, but they worked and learned together in a group or pairs. They could help others, argue, and discuss to obtain a specific purpose. The students learned better and made them easier during learning. As described in the interview result, the students learned vocabulary with classmates in groups. Another interviewee also pointed out a similar thing.

"When I find unknown words in reading, I always like to have a group working in learning vocabulary because learning with friends in groups is easier and faster to understand."

Nevertheless, memory strategies were the least popular strategies among the four strategies in consolidating the words they have been encountered. From table 7, the most frequently employed strategy was the students remember the new vocabulary by imagining or describing the word in my mind. The students frequently utilized memory strategies to recall the meaning of words. It was supported by the interview result. One interviewee agreed that memory strategies are their chosen strategies. 
"I try to imagine and describe the word in my mind when I memorize new vocabulary. It makes it easier to remember new vocabulary."

Furthermore, it was found that the respondents utilized the other two strategies (see table $3)$. Both cognitive and metacognitive strategies were equal frequently used.

Another finding of this research also revealed that there was no significant difference in the use of VLS by male and female students. This finding was similar to the findings of previous research conducted by Manuel [19] and Mustapha \& Hatta [20]. However, the results of Independent Sample t-test individual items for four VLS revealed a significant difference in the mean scores. The research showed that the male students had a higher mean score than female students in two individual items, involving one strategy in the social category (SOC) and one strategy in the metacognitive strategy (MET). The result was like the finding of Mustapha \& Hatta [20] research that reported male students utilized more VLS than male students. It was also revealed that female students had a higher mean score than male students in three individual items, involving one strategy in the social category (SOC) and two strategies in the cognitive category (COG). It was also confirmed by the previous research done by Subon [21] that female students employed more VLS than male students.

\section{CONCLUSION}

The aim of this research was to investigate the use of VLS by the seventh-grade students in SMP Negeri 1 Mlati, which consisting of 53 female students and 75 male students. Based on the finding of the research, there are three conclusions taken. First, the students were low strategy users of VLS and the score of overall strategy was 2.45. Second, social strategies were the most frequently used strategies employed by the students, and memory strategies were least. The third finding also revealed that there was no significant difference in the use of VLS among male and female students. Hence, it can be summed up that the seventh-grade students in SMP Negeri 1 Mlati utilize various of VLS in learning vocabulary. Pertaining to the result that the students belonged to low users of VLS, the teacher can introduce the strategies which might be employed by students to maximize their vocabulary learning in reading class.

\section{REFERENCES}

[1] S. B. Neuman and J. Dwyer, "Missing in Action: Vocabulary Instruction in Pre-K," Read. Teach., vol. 62, no. 5, pp. 384-392, 2009.

[2] E. M. Hatch and C. Brown, "Vocabulary, semantics, and language education," Cambridge language teaching library. pp. xii, 468, 1995.

[3] J. C. Richards and W. A. Renandya, "Methodology in Language Teaching: An Anthology of Current Practice." Cambridge University Press, New York, p. 255, 2002.

[4] D. G. Hennings, Reading With Meaning, Strategies for College Reading. New Jersey: Prentice-Hall, 1990.

[5] A. N. Rama, A. Rahim, and Alberth, "The Use of Schoology to Enhance Students' Reading Comprehension at Lakidende University," J. Lang. Educ. Educ. Technol., vol. 3, no. 1, 2018.

[6] Y. Zhihong, "Learning words," Forum Fam. Plan. West. Hemisph., vol. 38, p. 3, 2000.

[7] Y. Zhang, "The Use of Vocabulary Learning Strategies by Good and Poor Language Learners A case study of Chinese non-English major sophmores," Strategies, 2011. 
[8] L. Ghazal, "Learning Vocabulary in Efl Contexts Through Vocabulary," Novitas R., vol. 1, no. 2, pp. 84-91, 1997.

[9] S. Thornbury, "How to Teach Vocabulary.pdf." Prentice Hall, New Jersey, p. 185, 2002.

[10] C. Intaraprasert, "ESE students and vocabulary learning strategies: A preliminary investigation," p. 53, 2004.

[11] R. L. Oxford, Language Learning Strategies: What Every Teacher Should Know. Boston: Heinle \& Heinle, 1990.

[12] A. Wenden and J. Rubin, Learner Strategies in Language Learning. New Jersey: Prentice Hall, 1987.

[13] Peter Yongqi Gu, "Learning Strategies for Vocabulary Development," Reflections English Lang. Teach., vol. 9, no. 2, pp. 105-118, 2010.

[14] J. M. O’Malley, A. U. Chamot, G. Stewner-Manzanares, R. P. Russo, L. Küpper, and L. Kupper, "Learning Strategy Applications with Students of English as a Second Language," TESOL Q., vol. 19, no. 3, p. 557, 1985.

[15] N. Schmitt, A Taxonomy of Vocabulary Learning Strategies. New York: Cambridge University Press, 1997.

[16] L. Vygotsky, "Thought and language," Thought and Language. pp. 1-283, 2016.

[17] H. D. Brown, "Teaching by Principles, Second Edition," Teaching by Principles An Interactive Approach to Language Pedagogy. p. 2, 2000.

[18] R. E. Slavin, Cooperative Learning, Theory, Research and Practice. London: Allyn and Bacon Publisher, 1995.

[19] N. N. Manuel, "Evaluating Vocabulary Learning Strategies ( VLS ): Gender differences, the most and least used ( VLS ) among Angolan EFL Students at the Faculty of Arts ( Luanda , Angola )," vol. 10, no. December, pp. 483-504, 2017.

[20] A. A. Mustapha, S. Anisah, and M. Hatta, "The Use of Vocabulary Learning Strategies by Pre-Diploma Students in UITM MDAB programme," vol. 3, no. 2, pp. 65-76, 2018.

[21] F. Subon, "Vocabulary Learning Strategies Employed by Form 6 Students," Int. J. Sci. Res. Publ., vol. 3, no. 6, pp. 1-32, 2013. 